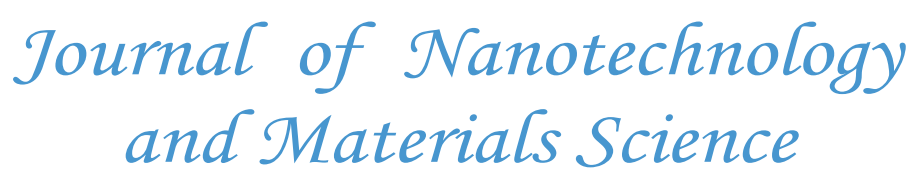

\title{
Nanoparticle Encapsulation for Antiretroviral Pre-Exposure Prophylaxis
}

\author{
Karl Khandalavala $^{1}$, Subhra Mandal ${ }^{2}$, Rachel Pham ${ }^{1}$, Christopher J. Destache ${ }^{2}$, Annemarie Shibata ${ }^{1 *}$ \\ ${ }^{1}$ Department of Biology, Creighton University, Omaha, NE, 68178, USA \\ ${ }^{2}$ School of Pharmacy and Health Professions, Creighton University, Omaha, NE, 68178, USA
}

*Corresponding author: Annemarie Shibata, HLSB RM 422, Department of Biology, Creighton University, Omaha, NE, 68178, USA, Tel: +1-402-280-3588, E-mail: annemarieshibata@creighton.edu

\begin{abstract}
HIV continues to be one of the greatest challenges facing the global health community. More than 36 million people currently live with HIV and, in 20152.1 million new infections were reported globally. Pre-Exposure Prophylaxis (PrEP) prevents HIV infection by inhibiting viral entry, replication, or integration at the primary site of pathogenic contraction. Failures of large antiretroviral drug (ARV) PrEP clinical trials indicate the current insufficiencies of PrEP for women in high-risk areas, such as sub-Saharan Africa. A combination of social, adherence, and drug barriers create these insufficiencies and limit the efficacy of ARV. Nanotechnology offers the promise of extended drug release and enhances bioavailability of ARVs when encapsulated in polymeric nano-particles. Nanoparticle encapsulation has been evaluated in vitro in comparative studies to drug solutions and exhibit higher efficacy and lower cytotoxicity profiles. Delivery systems for nanoparticle PrEP facilitate administration of nano-encapsulated ARVs to high-risk tissues. In this mini-review, we summarize the comparative nanoparticle and drug solution studies and the potential of two delivery methods: thermosensitive gels and polymeric nanoparticle films for direct prophylactic applications.
\end{abstract}

Received date: June 20, 2017
Accepted date: July 31, 2017
Published date: August 07, 2017

Citation: Annemarie Shibata, et al. Nanoparticle Encapsulation for Antiretroviral Pre-Exposure Prophylaxis. (2017) J Nanotechnol Material Sci 4(2): 53- 61.

DOI: $10.15436 / 2377-1372.17 .1583$

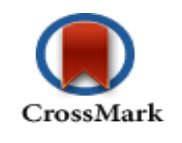

\section{Introduction}

Over the last fifteen years, international initiatives have designed more potent, new antiretroviral drugs(ARV) to reduce HIV infection and HIV-related deaths ${ }^{[1]}$. As a result, between 2000 - 2015, HIV infection rates fell 35\%, and Acquired Immune Deficiency Syndrome (AIDS)-related deaths fell $27 \%{ }^{[1]}$. Despite these recent successes, HIV infection and AIDS continue to be a challenging healthcare problem in the 21 st century. According to a report by the American Foundation for AIDS Research, over 36 million people worldwide continue to live with HIV-1 and 2.1 million new HIV infections were reported in $2015^{[1,2]}$. Of those newly infected individuals, $47 \%$ were women and $8 \%$ were children less than 15 years old ${ }^{[1]}$. Young people between the ages of 15 and 24 accounted for $35 \%$ of all new adult infections, with infection rates of young women in this age group accounting for $20 \%$ of the global sum of HIV infections ${ }^{[1,2]}$ In sub-Saharan Africa, 15 - 24 year old females are eight times more likely to be infected with HIV than their male counterparts $^{[2]}$. Greater than $80 \%$ of HIV infections are contracted through sexual transmission and $86 \%$ of female transmission has been attributed to heterosexual intercourse ${ }^{[3,4]}$. Factors such as mode of viral transmission, female physiology, and social, economic, and legal disadvantages contribute to increased rates of HIV infection in women. HIV/AIDS remains the leading cause of death for pre-menopausal women worldwide ${ }^{[5]}$. Given international efforts to reduce the annual global HIV infection rates by $90 \%$ by $2030^{[1]}$, highly efficacious therapeutic and preventative HIV therapeutic options must be available to at-risk populations, particularly women.

Post-infection HIV treatment using daily, highly active oral delivery of combination antiretroviral drug (ARV) therapies has significantly reduced HIV infection rates when such oral therapies are readily accessible and are reviewed elsewhere ${ }^{[6]}$. ART has been shown to significantly decrease the incidence of HIV transmission among serodiscordant couples when therapies are followed consistently by patient populations ${ }^{[7]}$. However, current oral therapies for (PrEP) are costly and are often in

Copyrights: (C) 2017 Annemarie Shibata. This is an Open access article distributed under the terms of Creative Commons Attribution 4.0 International License. 
limited supply in developing countries and/or to at-risk populations ${ }^{[8]}$. Pre-Exposure Prophylaxis (PrEP) holds the promise of eliminating new infections and thereby the associated risks of HIV infection. Consequently, there is a need for the development of innovative, cost-effective, and highly efficacious PrEP. Nanotechnology has garnered considerable interest in the field of HIV PrEP because of its potential to extend the release, target and increase cellular uptake, and improve the chemical, enzymatic and metabolic stability of therapeutic drugs ${ }^{[9,10]}$. Various types of nanocarriers such as dendrimers, liposomes, polymeric nanoparticles and nanosuspensions are being evaluated for $\mathrm{PrEP}^{[11]}$. Vaccines are another promising area of innovative PrEP research and development but are beyond the focus of this review. This mini-review article presents the history of and the latest development in those nanofabrications showing promise for female PrEP with specific emphasis on nanoparticle fabrications involving antiretroviral drugs (ARVs).

\section{Use of antiretroviral therapy (ART) for PrEP in females}

For a decade, it has been recognized that new infections of HIV must be reduced and that effective PrEP will be required to reach the worldwide goals for reducing the number of HIV infected individuals. The objective is to design PrEP that will block HIV at the mucosal membrane without causing tissue irritation or carrying the risk of developing resistance to ARVs. In order to eliminate the possibility of resistance, initial PrEP design involved the use of vaginal microbicides such as detergents, polyanionic inhibitors, or $\mathrm{pH}$ buffers that did not contain ARVs. Macromolecular entry inhibitors were largely unable to block HIV infection ${ }^{[12-14]}$. As concerns over drug-resistance waned $^{[15]}$, and awareness that women need access to cost-effective HIV prevention strategies increased, investigators focused on ARV-mediated prevention. ARVs acting before integration of viral genomic material into the host cells became the strongest candidates for preventative treatments $s^{[4,11]}$. Initially, two classes of reverse transcriptase inhibitors, nucleoside reverse transcriptase inhibitors (NRTIs) and non-nucleoside reverse transcriptase inhibitors (NNRTIs), were the focus of PrEP efforts/strategies. Two nucleoside reverse transcriptase inhibitors, tenofovir disoproxil fumarate (TDF) and emtricitabine (FTC) were delivered orally for PrEP. Daily oral regimen of TDF demonstrated a $48.9 \%$ reduction in HIV infection among injection-drug users ${ }^{[19]}$. Daily oral regimen of TDF/FTC (Truvada) showed similar reduction in the incidence of HIV infection (44\%) in men who have sex with other men ${ }^{[20,21]}$. The high efficacy of Truvada (44 $75 \%$ ) seen in clinical trials led to Truvada's approval for PrEP in both men and women by the US Food and Drug Administration in $2012^{[18,20,22-24]}$. Importantly, these clinical trials established a correlation between plasma drug levels and prophylactic capacity of ARV PrEP. Seroconversions are frequently associated with low plasma drug concentrations in treatment groups suggesting that maintenance of plasma drug levels is important for PrEP efficacy ${ }^{[25]}$. Low plasma drug levels associated with a lack of adherence and observed in the FEM-PrEP and VOICE clinical trials where adherence was below $40 \%$ resulted in reduced efficacy of TDF PrEP ${ }^{[26]}$.

TDF was also formulated into a vaginal gel and evaluated for pharmacokinetic, safety, and antiviral efficacy ${ }^{[16-18]}$. The focus of the well-known VOICE trial was to assess the effectiveness of daily treatment with vaginal TDF gel and oral TDF and oral TDF/FTC (Truvada) in preventing sexually transmitted HIV-1 infection in women. Results from VOICE reinforce the importance of adherence to PrEP regimens. No significant difference was seen between drug and placebo treatments either vaginally or orally. Drug levels detected in the blood were low or absent for the majority of participants unless they were older than 25 , married, or their sexual partner was older than $28^{[23]}$. CAPRISA 004 clinical trial investigated the efficacy of $1 \%$ TDF gel for PrEP revealing similar adherence-mediated effects. In this case, drug delivery specified for pre- and postcoital gel applications found the gel to be $39 \%$ effective in preventing HIV infection and concluded an overall efficacy of $54 \%$ in cohort with greater than $80 \%$ adherence. A subsequent study carried out over 2.5 years in 9 locations across South Africa demonstrated that adherence of high-risk female populations (> 70\%) exhibited enhanced PrEP for HIV, but only $20 \%$ of the overall sample size was in this cohort ${ }^{[27]}$. More recently, three double-blind placebo controlled randomized trials demonstrate that daily oral TDF-based PrEP is quite successful given adherence and detectable TDF-blood levels ${ }^{[28]}$. These three studies found that daily oral PrEP reduced the risk of HIV infection in women. The Partners PrEP study included 1785 Kenyan and Ugandan women with HIV-infected partners. PrEP efficacy was $66 \%$ and $71 \%{ }^{[29]}$. In the TDF2 study conducted in Botswana among heterosexual men and women, efficacy was $49 \%$ with a small sample size of 557 women $^{[18]}$. A tenofovir study in Bangkok (BTS) showed that PrEP reduced the risk of HIV infection in women by $79 \%{ }^{[19]}$. All five studies demonstrate that acquisition of HIV occurs during periods of low or no adherence to PrEP.

Taken together, these studies demonstrate that participant adherence directly influences PrEP efficacy. Surmounting the adherence barrier necessitates the development of cost-effective, easily used, and long-lasting PrEP fabrications.

\section{ARV loaded Polymeric Nanoparticles}

Polymeric nanoparticles for ARV drug delivery can encapsulate various drug formulations for selective and enhanced drug delivery. Polymeric NP pharmacokinetic and material development are reviewed elsewhere ${ }^{[12,30]}$. Nanoparticle sustained drug delivery is likely to reduce the required frequency of drug application for proper efficacy. Reducing dosing complexities and frequency are likely to increase treatment adherence and effectiveness while decreasing cost and high dosage toxicity. Current developments of ARV-encapsulated NP treatments for PrEP typically utilized poly(lactic-co-glycolic acid) (PLGA) based prophylactic modalities. Other polymers such as Cellulose Acetate Phalate (CAP) and Polycaprolactone (PCL) are being explored. Specific polymers, such as CAP, have anti-microbicidal function and may serve not only as a nanoparticle polymer but also enhance PrEP efficacy.

PLGA is a common nanoparticle polymer. Studies suggest that PLGA-NPs undergo endosomal uptake allowing for delivery of encapsulated drug directly to cellular cytoplasm and thus enhancing ARV drug uptake into the cell[ ${ }^{[2,3]}$. Cellular in vitro assays examined the efficacy of ARV in solution verses encapsulation of ARV in PLGA-NPs. In many studies, encapsulation of ARV in PLGA-NP has shown increased prophylactic efficacy of PLGA-ARV-NP as compared to ARV in solution alone. Mandal et al., 2016 encapsulated FTC in PLGA-NPs via a water-in-oil-in-water emulsion method ${ }^{[31]}$ (Table 1). In vitro 
TZM-bl and human Peripheral Blood Mononuclear Cell (PBMC) assays demonstrated that PLGA-FTC-NPs significantly reduced FTC IC $_{50}$ levels against HIV as compared with FTC solution ${ }^{[31,32]}$. PLGA-FTC-NPs protected PBMCs for up to 21 days post-HIV exposure ${ }^{[32]}$.

Table 1: Nanoparticle encapsulated ARV for PrEP in vivo and in vitro using film and gel delivery modalities.

\begin{tabular}{|c|c|c|c|c|c|c|c|}
\hline $\begin{array}{l}\text { Prophylac- } \\
\text { tic Modality }\end{array}$ & ARV & Drug Target & Drug Target & EE\% a/AE\%b & Level of Study & $\begin{array}{l}\text { Duration of } \\
\text { measurement }\end{array}$ & Results \\
\hline PLGA/SA & TFV & NRTI & Film & $\begin{array}{l}\text { AE: } 53.5 \% \pm \\
4.9 \% \mathrm{~b}\end{array}$ & SVF & $24 \mathrm{~h}$ & $\begin{array}{l}\text { PLGA/SA-TFV-Film sus- } \\
\text { tained drug release }(60 \% \text { re- } \\
\text { leased in } 24 \mathrm{hrs})(71)\end{array}$ \\
\hline PLGA & IQP-0528 & NNRTI/EI & Film & NR & Macaques & $24 \mathrm{~h}$ & $\begin{array}{l}\text { In vitro: } 51.65 \% \pm 7.22 \% \\
\text { drug release at } 24 \mathrm{hrs} \text {; In vivo: } \\
(72)\end{array}$ \\
\hline PLGA & $\begin{array}{l}\text { EFV-Free } \\
\text { TFV }\end{array}$ & NNRTI-NRTI & Film & $96.8 \pm 2.5 \%$ & $\begin{array}{l}\text { Female CD-1 } \\
\text { Mice }\end{array}$ & $24 \mathrm{~h}$ & $\begin{array}{l}\text { In vivo: } 2 \text { hr. burst release, } \\
\text { rapid drug decreases }(70)\end{array}$ \\
\hline SLS-PCL & DAP & NNRTI & NP Solution & $97.6 \% \pm 0.4 \%$ & $\begin{array}{l}\mathrm{TZM} / \mathrm{PBMC} / \\
\text { Mo-DC--T4 }\end{array}$ & $14 \mathrm{~d}$ & $\begin{array}{l}\text { TZM-bl: no } \mathrm{EC}_{50} \text { difference; } \\
\text { PBMC: 6.8-fold decrease } \\
\mathrm{EC}_{50} \text {; Mo-DC: 12.6-fold } \\
\text { EC }_{50} \text { decrease; moderate in } \\
\text { vitro cytotoxicity (46) }\end{array}$ \\
\hline CTAB-PCL & DAP & NNRTI & NP Solution & $97.9 \% \pm 0.3 \%$ & $\begin{array}{l}\text { TZM/PBMC/ } \\
\text { Mo-DC--T4 }\end{array}$ & $14 \mathrm{~d}$ & $\begin{array}{l}\text { TZM-bl: no } \mathrm{EC}_{50} \text { difference; } \\
\text { PBMC: } 6.3 \text {-fold decrease } \\
\mathrm{EC}_{50} ; \mathrm{Mo} \mathrm{DC}: 12 \text {-fold de- } \\
\text { crease } \mathrm{EC}_{50} \text {; high cytotoxic- } \\
\text { ity in all in vitro assays }(46)\end{array}$ \\
\hline PEO-PCL & DAP & NNRTI & NP Solution & $\begin{array}{l}97.6 \% \pm 0.1 \% \\
b\end{array}$ & $\begin{array}{l}\text { ICR } \\
\text { mice-topical }\end{array}$ & $24 \mathrm{~h}$ & $\begin{array}{l}\text { TZM-bl: no } \mathrm{EC}_{50} \text { difference; } \\
\text { PBMC: 3.8-fold decrease } \\
\mathrm{EC}_{50} \text {; Mo-DC: } 6.81 \text {-fold } \\
\mathrm{EC}_{50} \text { decrease; In vivo: 9-fold } \\
\text { increase DAP NP Vs. DAP } \\
\text { Sol. At } 24 \text { hrs. (47) }\end{array}$ \\
\hline PLGA & $\begin{array}{l}\mathrm{EFV}- \\
\mathrm{LPV} / \mathrm{r}\end{array}$ & NNRTI-PI/PI & NP Solution & $\begin{array}{l}\text { EFV: } 79.5 \%, \\
\text { LPV: } 79.8 \%, \\
\text { RTV: } 81 \%\end{array}$ & $\begin{array}{l}\text { TZM-bl } \\
\text { indicator cells }\end{array}$ & $48 \mathrm{~h}$ & $\begin{array}{l}\text { Similar } \mathrm{IC}_{50} \text { in combination } \\
\mathrm{NP} \text { than for each drug solu- } \\
\text { tion separately }(42)\end{array}$ \\
\hline PLGA & EFV & NNRTI & NP Solution & $44.5 \% \pm 2.7 \% \mathrm{a}$ & $\begin{array}{l}\text { TZM-bl } \\
\text { indicator cells }\end{array}$ & $48 \mathrm{~h}$ & $\mathrm{IC}_{50}: 54.6$-fold decrease (35) \\
\hline PLGA & SQV & PI & NP Solution & $\begin{array}{l}43.8 \% \pm 15.2 \% \\
\mathrm{a}\end{array}$ & $\begin{array}{l}\text { TZM-bl } \\
\text { indicator cells }\end{array}$ & $48 \mathrm{~h}$ & $\mathrm{IC}_{50}: 1.65$-fold decrease (35) \\
\hline PLGA & $\begin{array}{l}\text { MVC- } \\
\text { ETR-RAL }\end{array}$ & $\begin{array}{l}\text { EI-NNRTI-IS- } \\
\text { TI }\end{array}$ & NP Solution & $\begin{array}{l}91.0 \pm 9.9,16.8 \\
\pm 2.6,12.0 \pm \\
0.6 \mathrm{a}\end{array}$ & $\begin{array}{l}\text { TMZ-bl } \\
\text { indicator cells }\end{array}$ & $48 \mathrm{~h}$ & $\begin{array}{l}\mathrm{IC}_{50}: 8 \text {-fold decrease in com- } \\
\text { bination treatment relative to } \\
\text { the free drugs in combination } \\
\text { with one another }(36)\end{array}$ \\
\hline PLGA & FTC & NRTI & NP Solution & $\begin{array}{l}\text { EE: } 50.6 \pm 5.5 \\
\% \text { a }\end{array}$ & $\begin{array}{l}\text { TMZ-bl } \\
\text { indicator cells }\end{array}$ & $24 \mathrm{~h}$ & $\begin{array}{l}\text { 43-fold decrease in } \mathrm{IC}_{50} \text { in } \\
\text { the PLGA-FTC compared to } \\
\text { the FTC solution ( } 32 \text { ) }\end{array}$ \\
\hline PLGA & RPV & NNRTI & TMS & $98 \pm 0.7 \% \mathrm{~b}$ & $\begin{array}{l}\text { Hu-BLT } \\
\text { Mice-Topical }\end{array}$ & $7-8$ weeks & $50 \%$ protection $\mathrm{n}=12(65)$ \\
\hline PLGA & TDF & NNRTI & TMS & $52.9 \%$ a & $\begin{array}{l}\text { Hu-BLT } \\
\text { mice-topical }\end{array}$ & 4 weeks & $\begin{array}{l}100 \% \text { protection } 4,24 \text {, all in- } \\
\text { fected at } 7 \text { day time pt. }(67)\end{array}$ \\
\hline CAP & EFV & NNRTI & TMS & $\begin{array}{l}\text { EE: } 98.1 \% \pm \\
1.2 \% b\end{array}$ & $\begin{array}{l}\text { TMZ-bl indi- } \\
\text { cator cells }\end{array}$ & $3 d$ & $\begin{array}{l}\text { Combination NP significant- } \\
\text { ly higher } \% \text { antiviral activity } \\
\text { compared to EFV solution at } \\
\text { same concentration. ( } 57 \text { ) }\end{array}$ \\
\hline
\end{tabular}

$32,35,36,42,46,47,57,65,67,70-72$

$\begin{array}{lll}\mathrm{a} & \text { Encapsulation Efficiency }= & {\left[\left(\text { Drug }_{\text {measured }}\right) /\left(\text { Drug }_{\text {fabrication }}\right)\right]^{* 100}} \\ \mathrm{~b} & \text { Association Efficiency }= & {\left[\left(\text { Drug }_{\text {Fabrication }}-\text { Drug }_{\text {measured }} /\left(\text { Drug }_{\text {Fabrication }}\right)\right]\right.}\end{array}$

Chaowanachan et al., 2013 examined the encapsulation of low-solubility ARV drugs. Efavirenz (EFV), a non-nucleoside reverse transcriptase inhibitor (NNRTI), and saquinavir (SQV), a protease inhibitor, were encapsulated in PLGA-NP. PLGAEFV-NP were loaded using single solvent emulsion evaporation fabrication ${ }^{[33,34]}$. PLGA-SQV-NP were formulated by nanopre- 
cipitation $^{[35]}$. Individually, PLGA-EFV-NP and PLGA-SQV-NP showed increased efficacy over their respective free-drug solutions in TZM-bl indicator cell assays following 24hr pretreatment. PLGA-EFV-NP and PLGA-SQV-NP showed significantly reduced $\mathrm{ARV} \mathrm{IC}_{50}$ levels against $\mathrm{HIV}$ as compared to drug in solution (Table 1). Synergistic effects with free tenofovir (TFV) were also evaluated using TZM-bl cells by applying 1:1 equimolar $\mathrm{IC}_{50}$ drug concentrations at free EFV/SQV:TFV and PLGA-EVF/PLGA-SQV:TFV ratios. PLGA-EFV/TFV showed a 3-fold decrease in combined $\mathrm{IC}_{50}$ and PLGA-SQV/TFV exhibited a 20 -fold decrease in combined $\mathrm{IC}_{50}$ over their respective free drug treatments ${ }^{[35]}$ indicative of increased drug delivery to cells by nanoparticles.

To examine the potential synergistic anti-HIV activity of combination ART in nano-particle fabrications, encapsulation of single, dual or triple drug combinations of the entry inhibitor maraviroc, (MVC), the NNRTI etravirine (ETR), and the ISTI raltegravir (RAL) into PLGA-NPs were developed ${ }^{[36]}$ (Table 1). Drugs were encapsulated in PLGA using an emulsion-solvent evaporation protocol (Table 1). Single-encapsulation method avoids loading complexities often seen when nanofabricating drugs with different physiochemical profiles ${ }^{[37]}$. PrEP efficacy of PLGA-encapsulated treatments against HIV-BaL was examined using TZM-bl assays ${ }^{[35]}$. Only ETR-NP treatments exhibited decreased $\mathrm{IC}_{50}$ values while MVC-NP and RAL-NP had increased $\mathrm{IC}_{50}$ values compared to free-MVC/RAL. Tandem treatments of RAL-NP/MVC-NP, MVC-NP/ETR-NP, and ETR-NP/RAL-NP were evaluated using TZM-bl in vitro assays. Only ETR-containing fabrications showed improved efficacy, with 10-fold reduction in $\mathrm{IC}_{50}$ for $\mathrm{MVC} / \mathrm{ETR}-\mathrm{NP}\left(\mathrm{IC}_{50}: 0.38 \mathrm{nM}\right)$ and $\mathrm{RAL} /$ ETR-NP $\left(\mathrm{IC}_{50}: 0.40 \mathrm{nM}\right)$ paired treatments compared to the ETR solution (ETR-Sol) combined with MVC-Sol $\left(\mathrm{IC}_{50}: 3.02 \mathrm{nM}\right)$ and RAL-Sol $\left(\mathrm{IC}_{50}: 4.21 \mathrm{nM}\right)$. ETR-NP combinations were also three times more efficacious in blocking cell-cell HIV transmission. Drug synergy was only observed when ETR was paired with RAL or MVC and encapsulated into a polymeric nano-formulation. Interestingly, triple NP treatments did not show any increased potency over the double drug combinations $\left(\mathrm{IC}_{50}: 0.40 \mathrm{nM}\right)^{[36]}$. However, triple combination NP treatments were associated with higher intracellular concentrations than free-drug triple combination as measured by LC-MS/MS. Triple combination NP treatments were also protective against RTSHIV challenges in macaque cervico-vaginal explants tissue ${ }^{[34]}$. Differential encapsulation efficiencies for RAL were observed in fabrication of combination PLGA-EFV-RAL NPs. Oil-in-water emulsion with PLGA: Pluronic 127 at 1:2 w/w ratio resulted in EFV entrapment efficiency of 55.8\% and RAL at 98.2\% (Table $1)^{[38]}$. Despite different encapsulation percentages, the combination RAL-EFV-NPs showed lower inhibitory concentrations than drug solutions in in vitro TZM-bl assays (Table 1) ${ }^{[38]}$.

Multiple drug encapsulations of efavirenz (EFV) boosted by two protease inhibitors lopinavir/ritonavir (LPV/r) in PLGA-NPs using an emulsion-solvent-evaporation method with a high-pressure homogenization component to increase encapsulation efficiency were designed ${ }^{[38]}$. Encapsulation efficiency of EFV, LPV/r were 81.0, 79.8, and 79.5\%, respectively (Table 1$)^{[38,42]}$. TZM-bl cells inoculated with HIV- $1_{\mathrm{NL} 4-3}$ after treatment with PLGA-EFV-LPV/r NPs $24 \mathrm{hr}$ prior to infection. IC50 values for all encapsulated ARTs were in the nano-molar range (Ritonavir: 14.01nM, LPV: 16.54nM, EFV 30.73nM). EFV and LPV/r delivered by PLGA-NPs remained in different cellular compartments for as long as seven days in a HIV-1 ${ }_{\mathrm{NL} 4-3}$ challenged human $\mathrm{T}$ cell line as determined by sub cellular fractionation and HPLC analysis. Only ritonavir solution was found at detectable levels in cells at seven days while combination NPs showed measurable drug levels in membrane, nuclear, and cytoskeletal fractions indicating sustained release of drug through NP delivery ${ }^{[38,42]}$.

Polymer alternatives to PLGA such as poly( $\varepsilon$-caprolactone) (PCL) surface coated NPs were shown to enhance encapsulated drug bioavailability and intracellular retention ${ }^{[43-45]}$. Addition of Poly-Ethylene Oxide (PEO), Sodium Lauryl Sulfate (SLS), and Cetyl-Trimethyl Ammonium Bromide (CTAB) were surface modifications compared in PCL-NP fabrications. Each fabrication encapsulated dapivirine (DAP), a NNRTI, using a modified solvent displacement method ${ }^{[43,45]}$ that yielded higher DAP association efficiencies (Table 1) than previously reported with PLGA ${ }^{[46,47]}$. In TZM-bl assays infected with HIV-1 BaL virus, PEO-PCL-DAP-NP was less efficacious than free dapivirine solution while the two other surface treatments (SLS/CTAB) demonstrated lower $\mathrm{EC}_{50}$ values. However, CTAB surface coatings were found to be 4-fold more cytotoxic than the free dapivirine solution. PEO/SLS-PCL demonstrated significantly less cytotoxicity than free drug. Anti-HIV efficacy of these NPs using PBMC assays challenged with HIV after 2 hrs NP treatment resulted in $\mathrm{EC}_{50}$ values in the nano-molar range, 3-7 fold lower than free $\operatorname{drug}^{[47,48]}$. PEO-PCL exhibited the lowest cytotoxic concentration $\left(\mathrm{CC}_{50}\right)$ in PMBCs at $10^{5} \mathrm{nM}$, half that of SLS-PCL and approximately 200 -fold less than CTAB. These NPs inhibited HIV infection of monocyte-derived dendritic cells (Mo-DC) and CD4+ T cell co-culture for 14 days $^{[49,50]}$. Single drug applications to Mo-DC showed $\mathrm{EC}_{50}$ for NP-encapsulated DAP at 7-12 fold lower than free DAP. Cytotoxicity of NP treatments to Mo-DCs mirrored PBMC assays with CTAB-coated NP (PCL-CTAB) having the highest cytotoxicity $\left(\mathrm{CC}_{50}: 1,728 \pm 142 \mathrm{nM}\right), 20$-fold less than PCL-SLS $\left(\mathrm{CC}_{50}: 38,442 \pm 7,920 \mathrm{nM}\right)$, and 40 -fold less than PCL-PEO $\left(\mathrm{CC}_{50}: 76,984 \pm 8,467 \mathrm{nM}\right)^{[38]}$. PEO-PCL-DAP NPs were chosen for in vivo pharmacokinetic analysis due to their enhanced inhibition of infection and comparably low cytotoxicity profile ${ }^{[51]}$. Application of PEO-PCL-DAP NP or free DAP solution intravaginally to female mice showed enhanced retention of NPs in vaginal fluid. PEO-PCL-DAP NP retained drug levels above the previously established drug level for DAP for $24 \mathrm{hrs}$ while free DAP solution maintained threshold levels for $4 \mathrm{hrs}$. These results indicate the extended protective capacity of DAP NPs in vivo ${ }^{[51,52]}$.

Another nanoparticle polymer under investigation for PrEP is Cellulose Acetate Phthalate (CAP). CAP is unique to other functionally inert polymers because CAP has anti-microbicial properties that inhibit HIV-1 entry. CAP has been shown to bind to gp 120 and to gp 41 on HIV and to form six-helix bundles with R4 and R5 tropic viruses ${ }^{[3,54]}$. CAP also may destroy viral particles by stripping envelope glycol-proteins and causing HIV ${ }^{[53-55]}$. CAP is $\mathrm{pH}$ a sensitive polymer that depolymerizes at $\mathrm{pH}$ higher than $6.2^{[56]}$. Since vaginal mucosal $\mathrm{pH}$ is lower than 6.2, CAP-NPs are likely to remain stable in the acidic $\mathrm{pH}$ environment. CAP-EFV-NPs were formulated by nano-precipitation method and yielded an EFV entrapment efficiency of $98.1 \% \pm 1.2 \%$ (Table 1$)^{[57]}$. Short term (4 hr) and long term (3 day) PrEP of CAP-EFV-NPs against HIV-1 ${ }_{\text {NL4-3 }}$ challenge were assessed in vitro using TZM-bl assays. CAP-EFV-NPs significantly reduced HIV infection at concentrations below $50 \mathrm{ng} / \mathrm{mL}$ 
compared to EFV drug solution ${ }^{[57]}$. At 3 days the EFV solution had significantly lower antiretroviral activity compared to CAPEFV-NPs treatment at equivalent concentrations $(5 \mathrm{ng} / \mathrm{mL})^{[57]}$. CAP-EFV-NPs reduced the cytotoxicity of EFV on HeLa cells with significantly higher cell viability at $48 \mathrm{~h}$ and $96 \mathrm{~h}^{[57]}$. CAP may be another cost-effective polymer option for NP synthesis and PrEP.

\section{ARV loaded Polymeric NPs in TMS gel}

For ease of topical application to reproductive tissues some NP fabrications have utilized thermosensitive (TMS) gels. Topical gels coupled with polymeric NP encapsulated ARVs may offer direct application to principal sites of HIV exposure prior to sexual intercourse, ensure uniform drug application, and control drug kinetics for elongated release. Thermosensitivity modulates rheological properties by increasing viscosity as a function of increasing body temperature upon application to facilitate delivery and enhance vaginal retention ${ }^{[58,59]}$. Mechanisms for gelation have been explored ${ }^{[60]}$. Osmolarity is an important consideration for gels as failures in large clinical trials including CAPRISA-004 have been attributed to hyperosmolar gels causing inflammation and increased susceptibility to HIV-1 infection $^{[61]}$. Combinations of pluronic polymers (F127/F68) are used to tailor the rhelogical properties with citrate-buffered NP solutions, DMSO, and N-Methyl pyrrolidone ${ }^{[38]}$ (Figure 1). Recommended values of TMS gel fabrications are 380-1200 mOsm/ $\mathrm{kg}^{[62-64]}$. Initial gel fabrications were analyzed using in vitro cell assays that determined the delivery/translocation of Rhodamine 6G labeled PLGA-NPs (PLGA-Rhod6G-NP) through thermosensitive gels into HeLa cells. Fluorescence of PLGA-Rhod6GNP was observed in HeLa cells after 30 minutes of incubation showing rapid release and uptake of NPs into cells. Rhodamine $6 \mathrm{G}$ fluorescence was maintained for up to seven days in vitro ${ }^{[38]}$. PLGA-Rhod6G-NP delivered to the vaginal tissues of humanized mice showed uniform distribution in vaginal tissues. PLGA-Rhod6G-NP was specifically localized in the vaginal epithelium for up to 24 hours $^{[65]}$. As proof-of-concept experiments, CAP-EFV-NP were incorporated into TMS and examined efficacy ${ }^{[57]}$. HIV-1 ${ }_{\mathrm{NL} 4-3}$ antiviral efficacy was measured in vitro using TZM-bl assays following CAP-EFV-NP-TMS, CAP-NP-TMS, and EVF-TMS pre-treatment. TZMbl cells were challenged with HIV-1 four hours post-treatment and CAP-EVF-NP-TMS showed higher efficacy with $90 \%$ antiviral activity at $500 \mathrm{pg} /$ $\mathrm{mL}$ of EFV. These studies indicated enhanced efficacy of CAPARV-NP-TMS and expanded the study of TMS delivery to ARVs more likely to be used in human clinical studies ${ }^{[57]}$.

In vivo efficacy of PLGA-ARV-NP-TMS has been recently demonstrated in humanized mice. PLGA-Rilpivirine (RPV) -NPs were formulated by encapsulation using ion-solvent-evaporation technique for incorporation into TMS gel ${ }^{[66]}$. Kovarova et al., 2015 achieved 98\% RPV association efficiency and embedded their NPs in 20:1 Pluronic F127:F68 ratio TMS gel $^{[65]}$. Humanized BLT mice treated with PLGA-RPV-NP-TMS $(17.5 \mu \mathrm{g}$ RPV) were completely protected when challenged with high dose HIV-1 ${ }_{\text {RHPA }} 1.5$ hrs post-application. Only half of these mice were protected from HIV challenge $24 \mathrm{~h}$ after application of PLGA-RPV-NPs-TMS (Table 1) as determined by vRNART-PCR analysis. Further, vDNA analysis 7-8 weeks after the HIV challenge confirmed the seroconversion results from plasma vRNA by RT-PCR analysis ${ }^{[65]}$. Destache et al., 2016 exam- ined TMS gel fabrication using PLGA-TDF -NPs. PLGA-TDF -NPs were encapsulated using an oil-in-water emulsification ${ }^{[12]}$. An additive ion-pairing agent yielded a TDF encapsulation efficiency of $52.9 \%$ (Table 1$)^{[67]}$, significantly higher than the previously reported ${ }^{[36,37]}$ due to its water soluble properties. TMS was fabricated with the modification of neutral $7.4 \mathrm{pH}$ PBS instead of citrate buffer ${ }^{[50]}$. TDF-NP-TMS gel with three concentrations of TDF $(0.1 \%, 0.5 \%, 1 \% \mathrm{w} / \mathrm{v}$ TDF) were individually applied intra-vaginally to Hu-BLT mice. Following TDF-NP-TMS treatment mice were challenged with 2 transmission/founder HIV-1 strains at three time points. The four hour $(n=4)$ and 24 hour $(\mathrm{n}=6)$ challenge groups showed $100 \%$ protection against HIV1 challenge as determined by plasma viral load $(\mathrm{pVL})^{[67]}$. All mice challenged at seven days showed HIV-infection at 14 days post-inoculation, signifying TDF-NP-TMS gel capacity for intermediate protective capacity, but, currently, not for longer time durations $(>24 \mathrm{hrs})$.

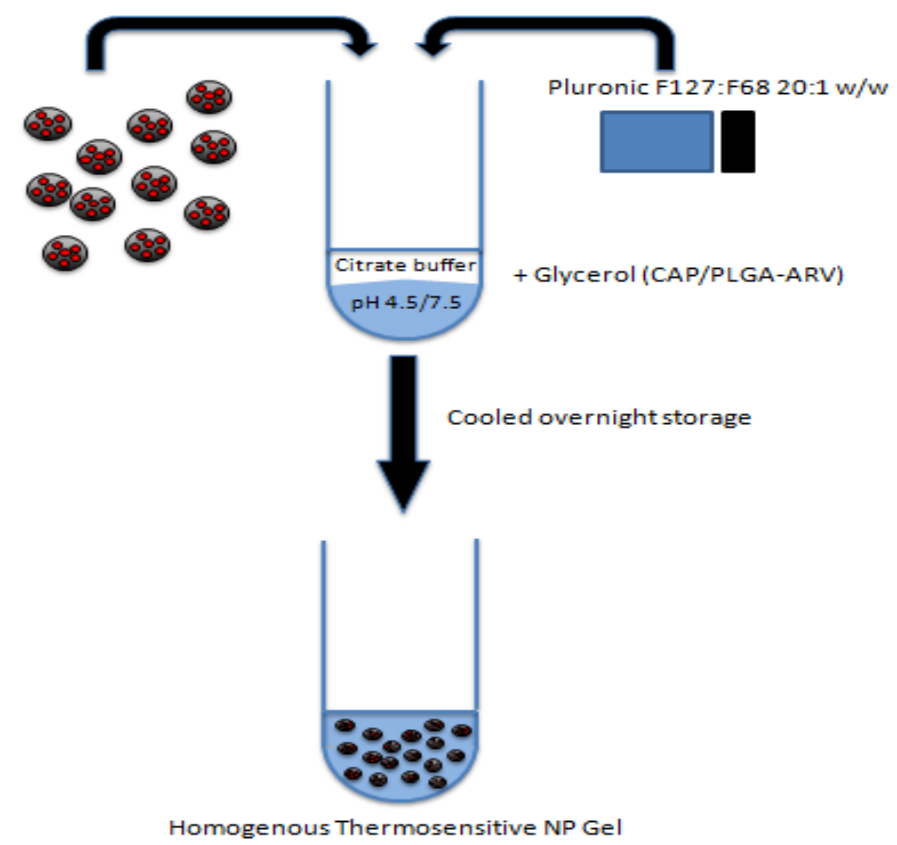

Figure 1: Fabrication of thermosensitive gel with NP-encapsulated ARVs for vaginal application of PrEP to high-risk tissues. ARVs encapsulated in polymeric nano-particles using oil-in-water emulsion technique with the organic phase comprised of ARVs, DMSO, N-methyl-pyrrolidone, and ethyl acetate emulsified in ultrapure water. ARVNPs are prepared in a citrate buffer with the addition of Plurionic F127 and F68 at a 20:1 ratio to the buffer for gelation. The solution is set overnight in a cooled environment. $\mathrm{pH}$ modifications are made for CAP-NP and PLGA-ARV-NP fabrications along with glycerol addition. Black-NPs, Red: ARVs, Blue: polymer ${ }^{[38]}$.

\section{ARV loaded Polymeric NPs in film}

Films serve as another platform to enhance the topical delivery of ARVs encapsulated in NPs to primary sites of HIV-1 exposure. Films offer some advantages to gels since films avoid the need for an applicator and reduce leakage issues ${ }^{[70]}$. Clinical trials of film-encapsulated dapivirine indicated the efficacy of these treatments in maintaining plasma drug levels comparable to that of gel fabrications ${ }^{[74]}$. Using solvent casting with glycerin as a plasticizer, prepared films of PLGA/stearylamine (SA)-Tenofovir-NPs were investigated for efficacy ${ }^{[71]}$. PLGA/ SA-Tenofovir-NPs were produced by double emulsion/solvent evaporation and demonstrated much higher NP-drug association 
efficiency (PLGA/SA: $53.5 \pm 4.9 \%$ ) than pure PLGA-based NPs $(18.5 \pm 2.5 \%)^{[71]}$. NP-embedded films were thicker and weaker than pure films, potentially complicating fabrication, handling, and applications, but they maintained minimum pharmaceutical thresholds. Like gels, the physiochemical properties of films must conform to physiologic osmolarity and $\mathrm{pH}$ levels to ensure safe vaginal applications ${ }^{[70,71]}$. PLGA/SA-Tenofovir-NP-film formulations were within physiologic thresholds ${ }^{[71]}$. Tenofovir release was sustained further in Tenofovir-NP-film fabrications compared to Tenofovir-NP and Tenofovir-film fabrications (Table 1).

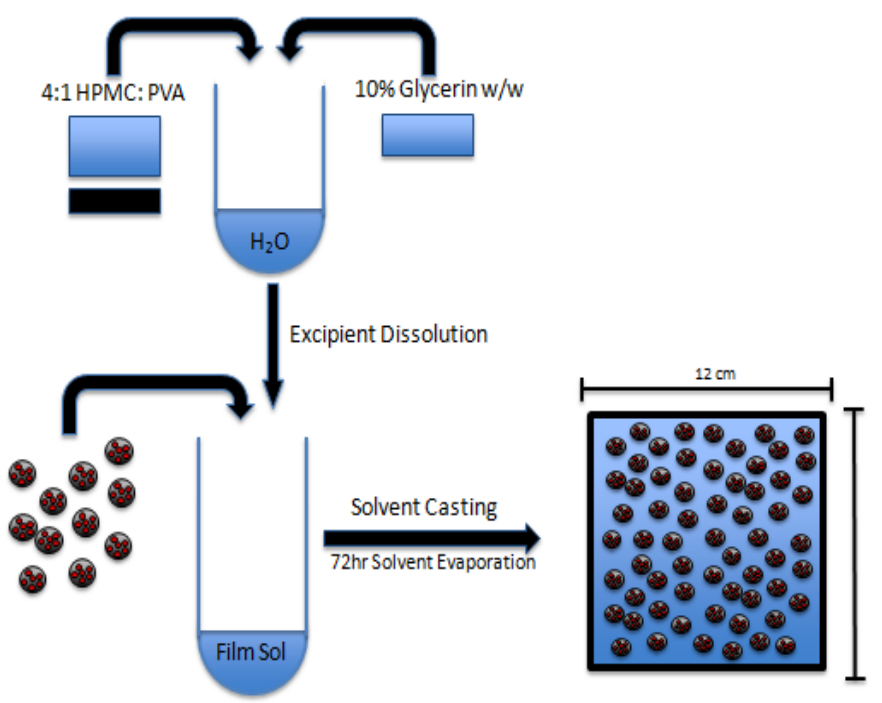

Figure 2: Fabrication of polymeric film with NP-encapsulated ARVs embedded into film for vaginal application of PrEP to high-risk tissues. Polymeric excipients HPMC and PVA were combined at a 4:1 ratio in a solution to $3 \% \mathrm{w} / \mathrm{w}$ of water containing $90 \%$ excipient polymers and $10 \%$ additional glycerin. ARV encapsulated PLGA NPs were added to the polymer-glycerin solution immediately before casting in $12 \mathrm{~cm} \mathrm{X}$ $12 \mathrm{~cm}$ polystyrene molds ${ }^{[70-73]}$.

Machado et al., 2016 examined PLGA-EFV-NPs embedded with tenofovir drug solution in polymeric films. PLGAEFV-NPs were fabricated by emulsion-solvent-evaporation ${ }^{[46]}$ and encapsulation efficiency of EFV was high (Table 1) ${ }^{[70,71]}$. EFV exhibited sustained release in vitro from NP-film fabrication with $40 \%$ burst release at one hour and sustained release at $20 \%$ over the next $24 \mathrm{~h}$ in simulated vaginal fluid (SVF). Nongel EFV-NP treatments released at a much faster rate indicating the potential of the film-matrix to extend NP drug release in SVF. PLGA-EFV-NP/TFV-films examined in vivo using female CD-1 mice showed enhanced retention of TFV for two hours but overall rapid decreases in drug concentration. Similar decreases have been observed with intra-vaginal tablet-tenofovir drug formulations in macaques and rabbits ${ }^{[75,76]}$. EFV concentrations were also sustained at early time points $(30 \mathrm{~min})$ using NP-EFV/TFV-solution films compared to EFV solution/TFV solution-film formulations, indicating the ability of NPs in films to elongate drug release of both $\mathrm{EFV}$ and TFV ${ }^{[71]}$.

Film fabrication differing in PVA: HPMC polymer excipient ratio has been designed. Polymer film embedded with IQP-0528, an NNRTI with entry inhibiting capabilities, was encapsulated in PLGA-NPs (PLGA/Eudragit S100-IQP-0582NPs) by double emulsion ${ }^{[77]}$. Films were optimized for physiologic physiochemical properties and drug loaded to $1.5 \% \mathrm{wt} /$ wt (drug/film $)^{[73,78]}$. In vitro drug release was measured in continuous flow in-line Franz cells $\mathrm{s}^{[7,79]}$ and showed significantly elongated release of IQP-0528-NP from films (24hr: $51.65 \% \pm$ $7.22 \%$ release) compared to free IQP-0528 films ( $1 \mathrm{hr}: 100 \%$ release). However, in vivo pharmacokinetic analysis on pigtailed macaques found that median drug levels at $24 \mathrm{hrs}$ were higher in the free-IQP-0528 films as opposed to the IQP-0528-NP-films (Table 1) $)^{[72]}$. All drug levels were well above IQP-0528 in vitro $\mathrm{IC}_{90}$ value $(0.146 \mu \mathrm{g} / \mathrm{mL})^{[80]}$ in the distal and proximal vaginal fluid indicating uniform coverage and enhanced retention of drug in the vaginal environment ${ }^{[72]}$.

Films have shown mixed results as a NP delivery modality. In vitro models with PLGA/SA-TFV NPs and PLGAEFV-NPs both showed elongated release compared to free-drug film fabrications ( 2 film articles). However, in vivo pharmacokinetic studies using PLGA-IQP-0582-NPs exhibited drug clearance rates similar to that of the IQP-0582 molecule in solution. Currently, there are no studies directly comparing gels and films as delivery systems for ARV-NPs.

\section{Conclusion}

Recent clinical studies have shown that PrEP can be highly efficacious given patient adherence. Widespread use of PrEP must be cost-effective and stable. New highly efficacious PrEP that can be delivered to at risk populations must be developed. Nanoparticle fabrications of ARVs delivered in thermosensitive gels or polymeric films may provide a means for low cost, highly effective PrEP and is an important goal of current PrEP research. There is an increased need for studies investigating new prophylaxis for women ${ }^{[21]}$. Prophylaxis that enhances current nanoparticle technology to deliver higher and sustained concentrations of ARV drugs is likely to provide enhanced efficacy. Future studies will show the viability of nanoparticle fabrications for PrEP.

Conflict of Interest: Authors declare no conflict of interest.

Funding: This project and publication were funded by NIAID 1 R15AI118550-01, 2015, (to A.S.) and NIAID R01AI117740-01, 2015 (to C.J.D.) project awards. 
Table 2: Abbreviations.

\begin{tabular}{|l|l|}
\hline Abbreviation & Name \\
\hline ART & Anti-retroviral therapy \\
\hline ARV & Anti-retroviral \\
\hline AZT/ZDV & Zidovudine (NRTI) \\
\hline EFV & Efavirenz (NNRTI) \\
\hline 3CT & Lamivudine (NRTI) \\
\hline LMV & Lamivudine (NRTI) \\
\hline Lf & Lactoferrin (NP) \\
\hline PEO & Poly(ethylene oxide) \\
\hline PCL & Poly(c-caprolactone) \\
\hline Hu-BLT & humanized bone marrow-liver-thymus mice \\
\hline PLGA & Poly(lactic-co-glycolic acid) \\
\hline TDF & Tenofovirdisoproxilfumarate (NRTI) \\
\hline TFV & Tenofovir (NRTI) \\
\hline LPN/r & Lopinavir/ritonavir PI \\
\hline PI & Protease Inhibitror \\
\hline IN & Integraseinihibitor \\
\hline SQV & Saquinavir (PI) \\
\hline MVC & Maraviroc (Entry inhibt) \\
\hline ETR & Etravirine (NNRTI) \\
\hline RAL & Raltegravir (IN) \\
\hline TMS & Thermosensitive Gel \\
\hline CAP & Cellulose Acetate Phthalate \\
\hline FTC & Emtricitabine (NRTI) \\
\hline RPV & Rilpivirine (NNRTI) \\
\hline Dapivirine & Entry Inhibitor \\
\hline EI & Dapivirine \\
\hline DAP & \\
\hline
\end{tabular}

\section{References}

1. AIDS by the numbers- AIDS is not over, but it can be. (2016) UNAIDS.

Pubmed | Crossref $\mid$ Others

2. Doblecki-Lewis, S., Kolber, M.A. Preventing HIV infection: Pre-exposure and postexposure prophylaxis. (2014) IUBMB Life 66(7): 453-461.

Pubmed | Crossref| Others

3. Statistics: Women and HIV/AIDS. (2016) amfAR : The Foundation for AIDS Research.

Pubmed |Crossref $\mid$ Others

4. Morris, G.C., Lacey, C.J. Microbicides and HIV prevention: lessons from the past, looking to the future. (2010) Curr Opin Infect Dis 23(1): 57-63.

Pubmed |Crossref | Others

5. Adimora, A.A., Ramirez, C., Auerbach, J.D., et al. Preventing HIV infection in women. (2013) J Acquir Immune Defic Syndr 63(S2): 168-173.

Pubmed | Crossref | Others

6. Okwundu, C.I., Uthman, O.A., Okoromah, C.A. Antiretroviral pre-exposure prophylaxis (PrEP) for preventing HIV in high-risk individuals. (2012) Cochrane Database Syst Rev (7): CD007189.

Pubmed | Crossref | Others
7. Cohen, M.S., Chen, Y.Q., Mc Cauley, M., et al. Prevention of HIV-1 infection with early antiretroviral therapy. (2011) N Engl J Med 365(6): 493-505.

Pubmed |Crossref |Others

8. Paltiel, A.D., Freedberg, K.A., Scott, C.A., et al. HIV Preexposure Prophylaxis in the United States: Impact on Lifetime Infection Risk, Clinical Outcomes, and Cost-Effectiveness. (2009) Clin Infect Dis 48(6): 806-815.

Pubmed | Crossref|Others

9. UNAIDS Report on the Global AIDS Epidemic 2013. (2017).

Pubmed | Crossref $\mid$ Others

10. Destache, C.J., Belgum, T., Goede, M., et al. Antiretroviral release from poly (DL-lactide-co-glycolide) nano-particles in mice. 2010) J Antimicrob Chemother 65(10): 2183-2187.

Pubmed |Crossref| Others

11. Abdool Karim, Q., Abdool Karim, S.S., Frohlich, J.A., et al. Effectiveness and safety of tenofovir gel, an antiretroviral microbicide, for the prevention of HIV infection in women. (2010) Science 329(5996): $1168-1174$.

Pubmed | Crossref| Others

12. Date, A.A., Destache, C.J. A review of nanotechnological approaches for the prophylaxis of HIV/AIDS. (2013) Biomaterials 34(26): 6202-6228.

Pubmed |Crossref $\mid$ Others

13. Williams, W.B., Liao, H.X., Moody, M.A., et al. Diversion of HIV-1 Vaccine-induced Immunity by gp41-Microbiota Cross-reactive Antibodies. (2015) Science 349(6249): 1253.

Pubmed | Crossref | Others

14. Pirrone, V., Wigdahl, B., Krebs, F.C. The rise and fall of polyanionic inhibitors of the human immunodeficiency virus type 1. (2011) Antiviral Res 90(3): 168-182.

Pubmed | Crossref| Others

15. Parikh, U.M., Mellors, J.W. Should we fear resistance from tenofovir/emtricitabine preexposure prophylaxis? (2016) Curr Opin HIV AIDS 11(1): 49-55.

Pubmed | Crossref | Others

16. Celum, C, Baeten, J.M. Antiretroviral-based HIV-1 prevention: antiretroviral treatment and pre-exposure prophylaxis. (2012) Antivir Ther 17(8): 1483-1493.

Pubmed | Crossref | Others

17. Anderson, P.L., Kiser, J.J., Gardner, E.M., et al. Pharmacological considerations for tenofovir and emtricitabine to prevent HIV infection. (2011) J Antimicrob Chemother 66(2): 240-250.

Pubmed | Crossref| Others

18. Thigpen, M.C., Kebaabetswe, P.M., Paxton, L.A., et al. Antiretroviral preexposure prophylaxis for heterosexual HIV transmission in Botswana. (2012) N Engl J Med 367(5): 423-434.

Pubmed |Crossref | Others

19. Choopanya, K., Martin, M., Suntharasamai, P., et al. Antiretroviral prophylaxis for HIV infection in injecting drug users in Bangkok, Thailand (the Bangkok Tenofovir Study): a randomised, double-blind, placebo-controlled phase 3 trial. (2013) The Lancet 381(9883): 20832090.

Pubmed | Crossref | Others

20. Grant, R.M., Lama, J.R., Anderson, P.L., et al. Preexposure Chemoprophylaxis for HIV Prevention in Men Who Have Sex with Men. (2010) N Engl J Med 363(27): 2587-2599.

Pubmed |Crossref|Others

21. Molina, J.M., Capitant, C., Spire, B., et al. On-Demand Preexposure Prophylaxis in Men at High Risk for HIV-1 Infection. (2015) N Engl J Med 373(23): 2237-2246.

Pubmed | Crossref| Others

22. FDA approves first drug for reducing the risk of sexually acquired

HIV infection. (2016)

Pubmed | Crossref $\mid$ Others 
23. Marrazzo, J.M., Ramjee, G., Richardson, B.A., et al. Tenofovir-based preexposure prophylaxis for HIV infection among African women. (2015) N Engl J Med 372(6): 509-518.

Pubmed | Crossref| Others

24. Kashuba, A.D.M., Patterson, K.B., Dumond, J.B., et al. Pre-exposure prophylaxis for HIV prevention: how to predict success. (2012) Lancet 379(9835): 2409-2411.

Pubmed | Crossref| Others

25. Cohen, M.S., Muessig, K.E., Smith, M.K., et al. Antiviral agents and HIV prevention: controversies, conflicts, and consensus. (2012) AIDS 26(13): $1585-1598$.

Pubmed |Crossref| Others

26. Van Damme, L., Corneli, A., Ahmed, K., et al. Preexposure Prophylaxis for HIV Infection among African Women. (2012) N Engl J Med 367(5): 411-422.

Pubmed|Crossref|Others

27. FACTS 001 Phase III Trial of Pericoital Tenofovir 1\% Gel for HIV Prevention in Women. (2016) CROI Conference.

Pubmed | Crossref $\mid$ Others

28. Thomson, K.A., Baeten, J.M., Mugo, N.R., et al. Tenofovir-based oral preexposure prophylaxis prevents HIV infection among women. (2016) Curr Opin HIV AIDS 11(1): 18-26.

Pubmed | Crossref| Others

29. Baeten, J.M., Donnell, D., Ndase, P., et al. Antiretroviral Prophylaxis for HIV Prevention in Heterosexual Men and Women. (2012) N Engl J Med 367(5): 399-410.

Pubmed | Crossref | Others

30. Ensign, L.M., Cone, R., Hanes, J. Nanoparticle-based drug delivery to the vagina: A review. (2014) J Control Release 190: 500-514.

Pubmed | Crossref | Others

31. Govender, T., Stolnik, S., Garnett, M.C., et al. PLGA nanoparticles prepared by nanoprecipitation: drug loading and release studies of a water soluble drug. (1999) J Control Release 57(2): 171-185.

Pubmed | Crossref| Others

32. Mandal, S., Belshan, M., Holec, A., et al. An enhanced Emtricitabine loaded long-acting nano-formulation for prevention or treatment of HIV infection. (2016) Antimicrob Agents Chemother 61(1): 14751516.

Pubmed |Crossref $\mid$ Others

33. Bilati, U., Allémann, E., Doelker, E. Sonication parameters for the preparation of biodegradable nanocapsules of controlled size by the double emulsion method. (2003) Pharm Dev Technol 8(1): 1-9.

Pubmed | Crossref | Others

34. Bilati, U., Allémann, E., Doelker, E. Development of a nanoprecipitation method intended for the entrapment of hydrophilic drugs into nanoparticles. (2005) Eur J Pharm Sci 24(1): 67-75.

Pubmed | Crossref| Others

35. Chaowanachan, T., Krogstad, E., Ball, C., et al. Drug synergy of tenofovir and nanoparticle-based antiretrovirals for HIV prophylaxis. (2013) PLoS One 8(4): 61416.

Pubmed | Crossref|Others

36. Jiang, Y., Cao, S., Bright, D.K., et al. Nanoparticle-Based ARV Drug Combinations for Synergistic Inhibition of Cell-Free and CellCell HIV Transmission. (2015) Mol Pharm 12(12): 4363-4374.

Pubmed |Crossref | Others

37. Calcagno, A., Nozza, S., Bonora, S., et al. Pharmacokinetics of the raltegravir/maraviroc/etravirine combination. (2011) J Antimicrob Chemother 66(8): 1932-1934.

Pubmed | Crossref| Others

38. Date, A.A., Shibata, A., Goede, M., et al. Development and evaluation of a thermosensitive vaginal gel containing raltegravir + efavirenz loaded nanoparticles for HIV prophylaxis. (2012) Antiviral Res 96(3): 430-436.

Pubmed | Crossref | Others
39. Lee, W., Park, J., Yang, E.H., et al. Investigation of the factors influencing the release rates of cyclosporin A-loaded micro- and nanoparticles prepared by high-pressure homogenizer. (2002) J Control Release 84(3): 115-123.

Pubmed | Crossref | Others

40. Dong, Y., Feng, S.S. Poly(D,L-lactide-co-glycolide) (PLGA) nanoparticles prepared by high pressure homogenization for paclitaxel chemotherapy. (2007) Int J Pharm 342(1-2): 208-214.

Pubmed | Crossref| Others

41. Mehta, A.K., Yadav, K.S., Sawant, K.K. Nimodipine loaded PLGA nanoparticles: formulation optimization using factorial design, characterization and in vitro evaluation. (2007) Curr Drug Deliv 4(3): 185193.

Pubmed | Crossref | Others

42. Shibata, A., McMullen, E., Pham, A., et al. Polymeric nanoparticles containing combination antiretroviral drugs for HIV type 1 treatment. (2013) AIDS Res Hum Retroviruses 29(5): 746-754.

Pubmed |Crossref|Others

43. Chawla, J.S., Amiji, M.M. Biodegradable poly( $\varepsilon$-caprolactone) nanoparticles for tumor-targeted delivery of tamoxifen. (2002) Int J Pharm 249(1-2): 127-138.

Pubmed | Crossref| Others

44. Ece Gamsiz, D., Shah, L.K., Devalapally, H., et al. A model predicting delivery of saquinavir in nanoparticles to human monocyte/macrophage (Mo/Mac) cells. (2008) Biotechnol Bioeng 101(5): 1072-1082. Pubmed |Crossref|Others

45. Shah, L.K., Amiji, M.M. Intracellular delivery of saquinavir in biodegradable polymeric nanoparticles for HIV/AIDS. (2006) Pharm Res 23(11): 2638-2645.

Pubmed | Crossref | Others

46. Neves das, J., Sarmento, B. Precise engineering of dapivirine-loaded nanoparticles for the development of anti-HIV vaginal microbicides. (2015) Acta Biomater 18: 77-87.

Pubmed |Crossref|Others

47. Neves das, J., Michiels, J., Ariën, K.K., et al. Polymeric Nanoparticles Affect the Intracellular Delivery, Antiretroviral Activity and Cytotoxicity of the Microbicide Drug Candidate Dapivirine. (2012) Pharm Res 29(6): 1468-1484.

Pubmed | Crossref | Others

48. Heyndrickx, L., Vermoesen, T., Vereecken, K., et al. Antiviral compounds show enhanced activity in HIV-1 single cycle pseudovirus assays as compared to classical PBMC assays. (2008) J Virol Methods 148(1-2): 166-173.

Pubmed | Crossref $\mid$ Others

49. Van Herrewege, Y., Vanham, G., Michiels, J., et al. A series of diaryltriazines and diarylpyrimidines are highly potent nonnucleoside reverse transcriptase inhibitors with possible applications as microbicides. (2004) Antimicrob Agents Chemother 48(10): 3684-3689.

Pubmed |Crossref | Others

50. Van Herrewege, Y., Michiels, J., Van Roey, J., et al. In vitro evaluation of nonnucleoside reverse transcriptase inhibitors UC-781 and TMC120-R147681 as human immunodeficiency virus microbicides. (2004) Antimicrob Agents Chemother 48(1): 337-339.

Pubmed | Crossref | Others

51. Neves das, J., Araújo, F., Andrade, F., et al. Biodistribution and Pharmacokinetics of Dapivirine-Loaded Nanoparticles after Vaginal Delivery in Mice. (2014) Pharm Res 31(7): 1834-1845.

Pubmed | Crossref | Others

52. Di Fabio, S., Van Roey, J., Giannini, G., et al. Inhibition of vaginal transmission of HIV-1 in hu-SCID mice by the non-nucleoside reverse transcriptase inhibitor TMC120 in a gel formulation. (2003) AIDS Lond Engl 17(11): 1597-1604.

Pubmed | Crossref | Others

53. Khalil, N.M., Carraro, E., Cótica, L.F., et al. Potential of polymeric nanoparticles in AIDS treatment and prevention. (2011) Expert Opin Drug Deliv 8(1): 95-112.

Pubmed | Crossref | Others 
54. Toit du, L.C., Pillay, V., Choonara, Y.E. Nano-microbicides: challenges in drug delivery, patient ethics and intellectual property in the war against HIV/AIDS. (2010) Adv Drug Deliv Rev 62(4-5): 532-546. Pubmed |Crossref| Others

55. Mallipeddi, R., Rohan, L.C. Nanoparticle-based vaginal drug delivery systems for HIV prevention. (2010) Expert Opin Drug Deliv 7(1): 37-48.

Pubmed | Crossref| Others

56. Mamo, T., Moseman, E.A., Kolishetti, N., et al. Emerging nanotechnology approaches for HIV/AIDS treatment and prevention. (2010) Nanomed 5(2): 269-285.

Pubmed | Crossref| Others

57. Date, A.A., Shibata, A., McMullen, E., et al. Thermosensitive Gel Containing Cellulose Acetate Phthalate-Efavirenz Combination Nanoparticles for Prevention of HIV-1 Infection. (2015) J Biomed Nanotechnol 11(3): 416-427.

Pubmed | Crossref| Others

58. Li, N., Yu, M., Deng, L., et al. Thermosensitive hydrogel of hydrophobically-modified methylcellulose for intravaginal drug delivery. (2012) J Mater Sci Mater Med 23(8): 1913-1919.

Pubmed | Crossref | Others

59. Gupta, K.M., Barnes, S.R., Tangaro, R.A., et al. Temperature and $\mathrm{pH}$ sensitive hydrogels: an approach towards smart semen-triggered vaginal microbicidal vehicles. (2007) J Pharm Sci 96(3): 670-681.

Pubmed |Crossref | Others

60. Ruel-Gariépy, E., Leroux, J.C. In situ-forming hydrogels-review of temperature-sensitive systems. (2004) Eur J Pharm Biopharm 58(2): 409-426.

Pubmed | Crossref| Others

61. Dezzutti, C.S., Rohan, L.C., Wang, L., et al. Reformulated tenofovir gel for use as a dual compartment microbicide. (2012) J Antimicrob Chemother 67(9): 2139-2142.

Pubmed | Crossref | Others

62. Friend, D.R. Pharmaceutical development of microbicide drug products. (2010) Pharm Dev Technol 15(6): 562-581.

Pubmed |Crossref|Others

63. Use and procurement of additional lubricants for male and female condoms: WHO/UNFPA/FHI360 (2012).

Pubmed | Crossref | Others

64. Cunha, A.R., Machado, R.M., Palmeira-de-Oliveira, A., et al. Characterization of Commercially Available Vaginal Lubricants: A Safety Perspective. (2014) Pharmaceutics 6(3): 530-542.

Pubmed | Crossref| Others

65. Kovarova, M., Council, O.D., Date, A.A., et al. Nanoformulations of Rilpivirine for Topical Pericoital and Systemic Coitus-Independent Administration Efficiently Prevent HIV Transmission. (2015) PLOS Pathog 11(8): 1005075.

Pubmed | Crossref| Others

66. Destache, C.J., Belgum, T., Christensen, K., et al. Combination antiretroviral drugs in PLGA nanoparticle for HIV-1. (2009) BMC Infect Dis 9: 198.

Pubmed|Crossref| Others

67. Destache, C.J., Mandal, S., Yuan, Z., et al. Topical Tenofovir Disoproxil Fumarate Nanoparticles Prevent HIV-1 Vaginal Transmission in a Humanized Mouse Model. (2016) Antimicrob Agents Chemother 60(6): 3633-3639.

Pubmed | Crossref | Others
68. Freeling, J.P., Koehn, J., Shu, C., et al. Anti-HIV drug-combination nanoparticles enhance plasma drug exposure duration as well as triple-drug combination levels in cells within lymph nodes and blood in primates. (2015) AIDS Res Hum Retroviruses 31(1): 107-114

Pubmed |Crossref|Others

69. Meng, J., Zhang, T., Agrahari, V., et al. Comparative biophysical properties of tenofovir-loaded, thiolated and nonthiolated chitosan nanoparticles intended for HIV prevention. (2014) Nanomed 9(11): 1595-1612.

Pubmed | Crossref | Others

70. Cunha-Reis, C., Machado, A., Barreiros, L., et al. Nanoparticles-in-film for the combined vaginal delivery of anti-HIV microbicide drugs. (2016) J Control Release 243(10): 43-53.

Pubmed | Crossref | Others

71. Machado, A., Cunha-Reis, C., Araújo, F., et al. Development and in vivo safety assessment of tenofovir-loaded nanoparticles-in-film as a novel vaginal microbicide delivery system. (2016) Acta Biomater 44(15): 332-340.

Pubmed | Crossref | Others

72. Srinivasan, P., Zhang, J., Martin, A., et al. Safety and Pharmacokinetics of Quick-Dissolving Polymeric Vaginal Films Delivering the Antiretroviral IQP-0528 for Preexposure Prophylaxis. (2016) Antimicrob Agents Chemother 60(7): 4140-4150

Pubmed|Crossref|Others

73. Ham, A.S., Rohan, L.C., Boczar, A., et al. Vaginal film drug delivery of the pyrimidinedione IQP-0528 for the prevention of HIV infection. (2012) Pharm Res 29(7): 1897-1907.

Pubmed | Crossref| Others

74. Bunge, K.E., Dezzutti, C.S., Rohan, L.C., et al. A phase 1 trial to assess the safety, acceptability, pharmacokinetics, and pharmacodynamics of a novel dapivirine vaginal film. (2016) J Acquir Immune Defic Syndr 71(5): 498-505.

Pubmed | Crossref | Others

75. Clark, M.R., Peet, M.M., Davis, S., et al. Evaluation of Rapidly Disintegrating Vaginal Tablets of Tenofovir, Emtricitabine and Their Combination for HIV-1 Prevention. (2014) Pharmaceutics 6(4): 616-631.

Pubmed | Crossref | Others

76. Pereira, L.E., Clark, M.R., Friend, D.R., et al. Pharmacokinetic and safety analyses of tenofovir and tenofovir-emtricitabine vaginal tablets in pigtailed macaques. (2014) Antimicrob Agents Chemother 58(5): 2665-2674.

Pubmed | Crossref | Others

77. Ham, A.S., Cost, M.R., Sassi, A.B., et al. Targeted delivery of PSCRANTES for HIV-1 prevention using biodegradable nanoparticles. (2009) Pharm Res 26(3): 502-511.

Pubmed | Crossref | Others

78. Akil, A., Agashe, H., Dezzutti, C.S., et al. Formulation and characterization of polymeric films containing combinations of antiretrovirals (ARVs) for HIV prevention. (2015) Pharm Res 32(2): 458-468.

Pubmed | Crossref | Others

79. Gao, Y., Yuan, A., Chuchuen, O., et al. Vaginal deployment and tenofovir delivery by microbicide gels. (2015) Drug Deliv Transl Res 5(3): 279-294.

Pubmed | Crossref | Others

80. Mesquita, P.M.M., Srinivasan, P., Johnson, T.J., et al. Novel preclinical models of topical PrEP pharmacodynamics provide rationale for combination of drugs with complementary properties. (2013) Retrovirology 10: 113 .

Pubmed | Crossref | Others
Ommega Online Publishers

Journal Title: Journal of Nanotechnology and Materials Science Journal Short Name: J Nanotech Mater Sci

\section{Journal ISSN: 2377-1372}

E-mail: nanoscience@ommegaonline.com

Website: www.ommegaonline.org 